\title{
Discussion on causes and accident liability confirmation in public sports injury accidents
}

\author{
Changwei Luo \\ Department of Physical Education, Jiangxi University of Technology, Nanchang Jiangxi, 330098, \\ China
}

Keywords: Public sports, Injury accident, Cause, Accident liability confirmation, Aountermeasure.

\begin{abstract}
. with the promotion of national fitness activities, popular sports career shows a high-speed rend. But during the process of promoting public sports activities, the probability of injury accidents are increasing. Only through comprehensive control and rectification of its causes and accident liability can optimize the operation framework of public sports activities and realize the sports injury treatment procedure with accountability while importing the overall project treatment measures and effectiveness. This article starts from the time background of public sports injury accident liability research, makes intensive explanation on accident causes and the confirmation of legal liability, and makes brief analysis on the treatment mechanism, aiming at improving the public understanding of sports injury accidents while proposing relevant recommendations so as to strengthen management effectiveness and realize the complementation of benefits.
\end{abstract}

\section{Analysis on the time background of public sports injury accident liability}

The launch and promotion of nationwide fitness campaign has improved the public passion for sports games greatly. The public activity and initiative for sports activities and sporting events have been enhanced obviously compared as before, and it is exactly because of the specialty of the sports form that it is very likely to lead to injuries during the process of promoting sports activities. Once sports injury accident happen, I will result the damage to related personnel mentally and physically, as well as serious impact on the regular sports order. In college sports events, accidents usually happen in campus sports games. Regarding the confirmation of liability, school is the first one to assume the liability and bear the compensation by judicial judgment which will brings about huge economic pressure and social stress to the school. Thus, how to correctly handle sports injury accident liability confirmation procedure is of great social significance.

\section{Analysis of causes of public sports injury accident}

When analyzing causes of public sports injury accident, researchers must comprehensively consider the specific condition and environmental parameter of accident happening to ensure the establishment of targeted handling methods and control measures. For example, in reality, if public sports injury accident happens in profitable gyms, the majority of reasons may be the loopholes in management and supervision. Thus any harmful sports event accidents happened to the public should ask for the site operator to take liability, which is not always reasonable. The manager of public sports facilities should undertake the due obligations for public physical fitness risk.

\section{Cause of public sports site management}

There will be organizer and mangers in sports events but problems will happen during the sports events ongoing when managers do not take effective safety protection or control of the sports projects and the criterion cannot be established for sports activities' secure and orderly operating[1]. Thus, sports supervisors should improve the time effectiveness while enhancing their self-management quality and supervisory capability. It is worth noticing that for the project management of sports activities, manager's responsibility is more important than their management knowledge and 
theoretical framework. Firstly, sports supervising officer must improve the scientificity of their training measures if wanting to achieve effectiveness to ensure the activity intensity and difficulty in accordance with public demand. Secondly, enhance the management strictness on sports activity especially establish control pre-arranged planning on some factors and problems which are likely to lead to injury accidents. Thirdly, if the sports events have the competitiveness, mangers should make effective security guidance for participants and make centralized examination on the site and facilities for sports activities.

\section{Public weak awareness of security}

Weak awareness of security of participant form a certain point of view is one of causes to lead to the injury accidents in sports activities. Participants do not make comprehensive analysis on sports events with weak self-protection capability. During the sports event operation, relevant departments must formulate specific requirement and standards, and some force majeure factors or problems will show up if participant cannot conduct corresponding sports activities based on the standardized requirement. For example, in skating or skiing places, coaches will make learning requirement and basic item index based on the trainee's learning level. But some trainees always operate not in accordance with the coach's teaching procedure when they are learning with higher proficiency assessment on their own sports level, which will lead to the occurrence of sports injury accidents.

\section{The public lack security emergency rescue ability}

Injury accidents happening in sports activity will lead to serious security problem even threatening to their life, which requires for the public to improve their own crisis management awareness. But one of major reasons to lead to the accident happen to the badness is the public weak self-emergency rescue ability, especially when some participants join in some strong competitive sports events so that security problems are more likely to happen. But the parties involved have not established effective management mechanism and control measures with no effective understanding and management on the emergencies so that when once accident happen, they fail to use emergency rescue knowledge so that it brings about huge damage. This is to say, only through ensuring scientific security rescue awareness and management ability can establish specific analytical mechanism on detailed problems to guarantee using emergency rescue principle and measurements to provide the injured with valuable rescue time and reduce the deterioration of sports injury accidents.

\section{Potential safety hazards in sports felicities}

During the process of sports activity establishment and operation, managers must make comprehensive analysis and control on the item management framework but also should focus on the analysis on sports activity operation site and environment when managing sports items, improve facility and site security, and ensure to establish safer sports activity procedure while improving the participants' health index. It is worth noticing that in sports activities, sports instrument and facility will be seriously worn out due to long-term use. If the managers cannot make timely rectification and control, there will be severe security problems with potential hazards remained. Especially some outdoor security facilities. Due to the outdoor environment and human use, equipment are rusted and loose, which will make sports participants' injury accidents happening. Thus, only when related management units improve secure management awareness, strictly standardize equipment layout and construction maintenance can they fundamentally improve the equipment security factors and ensure the decrease of probability of overall injury accidents [2].

\section{Analysis on public sports injury accident legal liability confirmation}

\section{Public sports injury accident legal liability allocation}

To make a comprehensive analytical confirmation of public sports injury accident liability, we should improve the perception structure of security item and ensure to establish effective legal liability 
allocation mechanism. Especially when the sports injury accidents happen to public participants, original management structure will change accordingly and related personnel's must implement necessary responsibility to make sure the sports injury accident can be optimally handled to establish the best liability confirmation structure and mechanism. For example, when serious injury accident happens inside the college sports games, the most important management mechanism and administration authority is the guardianship. At this time, school as the subject unit for students to participate in sports activities must assume the primary liability of guardian. Based on the regulation of civil law, the guardian must be responsible for the human life and property security of guardianship object. There exist no guardian demand legally for the guardian school but during the time when students taking lessons in the school, the school has the basic responsibility for guarding, protecting and managing students' life safety. Once accidents happen, school must assume the liability [3].

\section{Public sports injury accident legal liability confirmation}

When sports participants receive human injuries, managing staffs must make specific analysis on detailed problems so as to establish effective liability allocation to make sure the sports injury accident can be assumed accountability to guarantee the safeguard of participants' basic rights. This is the fundamental of public sports injury accident legal liability confirmation, especially for negligent injuries, only through assuming related legal liability can guarantee the soundness of legal practice structure and related parties in charge can take necessary civil responsibility while defending for life and health right. This article lists some specific requirements confirmed for civil liability in public sports activities. During the civil liability handling process, the most important measure standard is the doctrine of liability fixation, which means to establish the balance between fault liability handling principle, equal liability processing principle and non-fault liability treatment principle. Public sports injury accident is classified into ordinary civil trespass mainly using the fault liability processing principle based on the legal regulation of the first clause, article 106 in "General Rule of Civil Law" that, when citizens or legal person brings about damage to the country or collective assets due to their own fault or violate other people's properties or human security, related party must assume legal liability. This has clearly show that when the public participate sports activities, once injury accidents happen, the sports site operator must take civil legal liability.

Due to the particularity of public sports activities such as in basketball games the injury in the ankle because of grabbing rebounds, it is no need to assume the liability for tort as it is impossible during the activity to notice whether others have the sign of injury. Under the precondition that both parties have reached the consensus of assumption of risk, the public sports events can be developed very well. It can be seen that the injurer in sports activities can be exempted from liabilities due to the consensus of the assumption of risk with the other party. But this kind of consensus is not stipulated by the law but exist in sports activity itself as its nature [4]. Therefore, during the public sports injury accident legal liability confirmation, the rule of assumption of risk can be considered.

\section{Analysis on public sports injury accident handling mechanism}

\section{Analysis on the basic principles of public sports injury accident handling}

When coping with the public sports injury accidents, managing staffs must establish specific analysis mechanism based on practical issues to makes sure the control item can be proceeded step by step based on related principles. Firstly, accident managing staffs must take positive prevention principle to handle the possible potential hazards timely, strengthen the precaution standardization and control effectiveness, substantially protect the operation norm of sports activity, and appropriate deal with specific accident while improve the level of problem-solving[5]. Secondly, managing staffs must operate the proper principle of objective and fair, establish specific analytical measurement based on detailed problems, and improve the effectiveness of item handling so as to make sure the public sports injury accidents can be optimally managed and controlled. Thirdly, managing staffs must keep 
timeliness principle in mind, and ensure the time nodes to be feasible while improving managing level so as to truly improve handling effectiveness of injury accident treatment.

\section{Analysis on the basic procedure of public sports injury accident handling}

When sports injury accident happens, managing staffs must take timely rescue measures on the injured group. If no condition for on-site handling, it is a must to contact the guardian timely. Once serious injury accident happen, managing staffs must report the practical situation to administrative department so as to guarantee the order recovery. For example, for school sports injury accident, it is possible to ask educational administrative department for help for treatment and supervisory handling so as to make sure the school teaching order can be effectively maintained. In addition, school must consult with student's parents based on the specific problem. Under the condition of mutual resources, the educational administrative department can comprehensively mediate the issue to guarantee the accident procedure to be reasonable and legitimate. After receiving the conciliation application, educational administrative department must complete the problem mediation work from the date of receiving specific problem within 60 working days so as to make sure the conciliation can terminate after the school and the student reach basic mediation agreement.

\section{Analysis on the compensation mechanism of public sports injury accident handling}

After determining related liability, managing staffs must take effective handling measurements based on specific problems to make sure the control structure and control item can be comprehensively implemented. Established related economic compensation and moral reparation based on the responsibility degree so as to fundamentally guarantee the effectiveness of the compensation and maintain the injured person's primary interests. For example, students in campus must be identified centralized according to related administration laws and regulations once sports injury accident happens [6].

\section{Comprehensive suggestions on public sports injury accident}

When handling public sport injury accidents, managing staff must adhere to the principle of prevention and security first, and guarantee the min probability of security accident occurrence to a degree. Truly achieve evidence-based, and proof-oriented control measurement based on the law and regulation. Related item managing staffs must improve their comprehensive quality, take solid security checking measurements, implement regular checking and non-scheduled spot checking combined management measurement, and improve the public awareness of security, so as to guarantee the public basic rights to participate in sports activities as well as to improve the public consciousness of defending their own legal rights.

\section{Conclusion}

In a word, the whole society must attach more importance to the public sports injury accidents, strengthen the control measurements on accident liability confirmation, and try best to eliminate the potential security hazards of management item while enhancing examination force, and make specific analysis on concrete issues, to fundamentally solve the hidden problems which may lead to sports injury accidents so that public sports events can obtain benign development.

\section{Acknowledgement}

This article is the staged achievement of project approved by Jiangxi Province Sports Bureau in 2016 (Project No.: 2016008). 


\section{References}

[1] Jing Houliang, Han Yong. Restrict of sports facility standard to nationwide fines development and the countermeasures - from the perspective of the relationship between sports standard and sports injury accident liability, Journal of Tianjin University of Sport, 2013,28(03):239-244.

[2] Zhao Yi. How youth school sports injury disputes applied to laws----_(2011) Analysis on baoshao minchuzi No.113 paper of civil judgement, Sports and Science 2015,36(02):44-49.

[3] Lin Baoer, Liu Yilong, Chen Zhizhen, etc. Analysis on influence of secondary vocational school sports injury accident on accident subject and accident initial countermeasures, Sports Teachers \& Friends, 2014,32(06):63-65.

[4] Yin Fei, Zhao Yi. Interpretative theory: new approaches for sports imputation applicable to assumption of risk, Journal of Wuhan Institute of Physical Education | $J$ Wuhan Inst Physi Edu, 2015,49(06):41-44.

[5] Xiao Wanfu. Studies on school sports injury accident imputation and compensation-based on 50 cases of school sports injury accident case studies, Huazhong University of Science and Technology, 2014.

[6] Liu Jingchun, Fei Ying. Studies on security guaranty mechanism in students' sports injury accident treatment, Bulletin of Sport Science \& Technology, 2014,19(11):19-19,29. 